\title{
PECULIARITIES OF DEVELOPMENT OF STRUCTURAL HETEROGENEITY IN THE FUSION ZONE OF PEARLITE STEEL WITH AUSTENITIC NITROGEN-CONTAINING WELD METAL*
}

\author{
V.P. ELAGIN, V.N. LIPODAEV and G.N. GORDAN \\ E.O. Paton Electric Welding Institute, NASU \\ 11 Kazimir Malevich Str., 03680, Kiev, Ukraine. E-mail: office@paton.kiev.ua
}

\begin{abstract}
The peculiar features of development of structural heterogeneity at high-temperature heating in the unstable fusion zone of the austenitic weld with the pearlite steel were considered. It was shown that one of the factors influencing the high nickel content in the weld and low heat input of welding on reduction of width of ferrite interlayer is the decrease in overheating and degradation of carbides in the HAZ metal. However, these changes do not prevent the film precipitation of carbides and embrittlement of metal between the fusion zone and the HAZ. The alloying of austenitic weld metal with nitrogen, formation of nitride particles being more stable than the carbides, and refining the grains facilitate the increase in stability of structure, inhibition of carbide reactions and more uniform distribution of carbides in the fusion zone with pearlite steel, which improves the properties of welded joints of dissimilar steels. 14 Ref., 7 Figures.
\end{abstract}

Keywords : arc welding, welded joints of dissimilar steels, fusion zone, structural heterogeneity, diffusion of carbon, austenitic weld, nickel, nitrogen, decarburized zone, carburized zone, heat affected zone

During manufacture and repair of petrochemical, oil refining, power and other technological equipment the welded joints of dissimilar austenitic and pearlitic steels are applied, which operate at the high (above $350{ }^{\circ} \mathrm{C}$ ) temperatures. To the joints of dissimilar steels the joints of heat-resistant alloyed steels with austenitic weld are also referred produced in case when the postweld heat treatment is impossible. The welding of such steels is carried out with the use of austenitic materials with a high (more than $13 \%$ ) nickel content. At the same time, the compliance of nickel content in the weld metal with the level of alloying of the pearlite steel and operating temperature is provided. The non-compliance of this condition results in development of structural heterogeneity in the fusion zone of the pearlite steel and the austenitic weld as a result of redistribution in carbon diffusion. Such a fusion zone is considered to be unstable [1].

The characteristic features of structural heterogeneity in the unstable fusion zone is the presence of interlayers, i.e. the carburized one with a high hardness in the transition layer of austenitic weld and the ferrite one with a low hardness in the HAZ of pearlite steel. The diffusion of carbon is facilitated by the gradient of its thermodynamic potential between the austenitic weld and the pearlite steel [1-3]. In the austenitic weld it has lower values due to the presence of strong carbide-forming elements such as chromium, molybdenum, vanadium, etc. which bind carbon into carbides. In the pearlite steel a higher value of potential is caused by the presence of unstable carbides and free carbon in the solid solution.

The transportation of carbon in the unstable fusion zone occurs according to the mechanism of both atomic and reactive diffusion [2]. During the atomic diffusion free carbon in the solid solution of metal is moved towards a stronger carbide-forming element. The reactive diffusion occurs as a result of carbide reactions which proceed with the dissociation of less stable carbides, diffusion of carbon to the fusion zone and the formation of more alloyed carbides. The decomposition of carbides in the HAZ is facilitated by the reduction in carbon content in the solid solution and a high temperature of heating during welding [4] or during service [3]. There is no unanimous opinion about the nature of welding heat input affecting the width of ferrite interlayer. In work [1] it was shown that the reduction in welding heat input contributes to its increase, and in work [5], on the contrary, it caus-

\footnotetext{
*According to the materials of the paper presented at the International Conference «Arc welding. Materials and quality» (Volgograd, RF, May 31-June 3, 2016).
} 


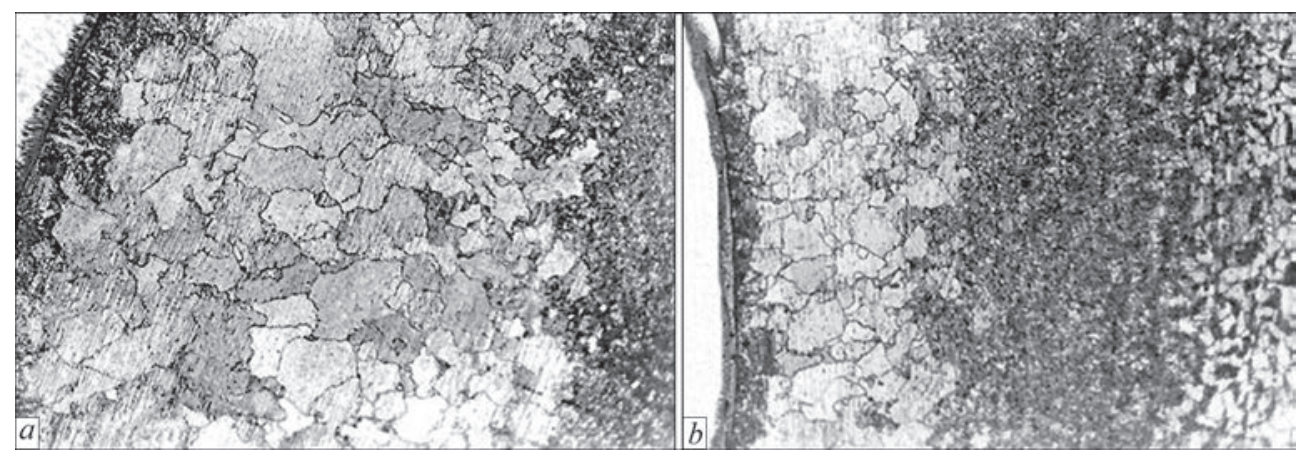

Figure 1. Microstructure (x100) of HAZ metal with ferrite interlayer of steel 20 in single-layer metal of type 08Kh25N40M7 deposited in $\mathrm{CO}_{2}+5 \% \mathrm{~N}_{2}$ at heat input of $7.9(a)$ and $4.1(b) \mathrm{kJ} / \mathrm{cm}$ and heating at $550{ }^{\circ} \mathrm{C}$ for $3000 \mathrm{~h}$

es its decreases at the reduced power density of laser treatment.

The application of high-nickel welding consumables is the most effective way to reduce the structural heterogeneity [1-3]. The effect of nickel is explained by increase in thermodynamic activity and reduction in the solubility of carbon in austenite [1].

However, at the unstable fusion zone a high nickel content in the weld, even in the amount characteristic for nickel alloys, does not fully prevent the carbon diffusion and the formation of structural heterogeneity. It was established in the fusion zone with low-carbon steel [6], where the carbon is in the composition of unstable cementite, or with heat-resistant alloyed steel with the structure of martensite in the HAZ metal [4]. The presented review demonstrates that until the present time the mechanism of structural heterogeneity formation in the unstable fusion zone of heterogeneous steels and the influence of nickel on it was not fully disclosed.

The positive effect of the austenitic weld alloying with nitrogen on reduction of carbon diffusion at the zone of its fusion with pearlite steel is known [7]. Nitrogen, the same as nickel, contributes to thermodynamic activity of carbon [8]. Moreover, nitrogen can be included into the composition of carbides, changing their composition and stability as well as forming nitrides with such elements as titanium, niobium, chromium, etc., which are more stable than carbides $[9,10]$. This fact, apparently, will influence the reactive diffusion of carbon. Earlier, the investigations of influence of the austenitic weld alloying with nitrogen on development of the decarburized interlayer in pearlite steel were not carried out. Taking into account the positive effect of nitrogen on properties of the austenitic weld metal [11] and that of welded joints of dissimilar steels [12], such investigations represent a scientific and practical interest.

The aim of this work is the comparison of effectiveness of influence of the austenitic weld alloying with nitrogen and nickel on development of structur- al heterogeneity in the unstable zone of fusion with pearlite steel.

To conduct investigations the single layer beads were deposited on the plate of steel 20 of $22 \mathrm{~mm}$ thickness using mechanized welding in shielding gas using austenitic wires of $1.2 \mathrm{~mm}$ diameter with the alloying of type 08Kh20N9G7T, 08Kh20N25M8G8 and 08Kh25N40M7. These wires are recommended for welding of dissimilar steels in the structures operating at different temperatures [1]. As a shielding gas Ar, $\mathrm{CO}_{2}, \mathrm{~N}_{2}$ and their mixtures $\mathrm{CO}_{2}+5-80 \% \mathrm{~N}_{2}$ were used, which allowed obtaining the nitrogen content in the amount of 0.04-0.06 and 0.12-0.39 wt.\%, respectively, in the metal of austenitic deposit. The surfacing was performed at heat input of 4.1 and $7.9 \mathrm{~kJ} / \mathrm{cm}$ at the following mode parameters: $I_{\mathrm{w}}=240-260 \mathrm{~A}, U_{\mathrm{a}}=$ $=24-26 \mathrm{~V}, v_{\mathrm{w}}=16$ and $25 \mathrm{~m} / \mathrm{h}$. In order to develop the structural heterogeneity, the welded joints were subjected to furnace heating at $550^{\circ} \mathrm{C}$ for 1000,1500 and $3000 \mathrm{~h}$.

The choice of heating temperature equal to $550{ }^{\circ} \mathrm{C}$ and carbon steel 20 as the base metal, containing no active carbide-forming elements, allowed obtaining a structural and phase instability which resulted in the development of structural and mechanical heterogeneities in the fusion zone. To reveal the structure of metal the metallographic etching of microsections was applied in $5 \%$ alcoholic solution of nitric acid. The hardness of metal was measured using PMT-3A device at load of $0.2 \mathrm{~N}$, and the distribution of carbon was determined using «Cameca» microanalyzer SX-50.

The investigations showed that after the long heating a ferrite interlayer is formed in the HAZ of pearlite steel of all the variants of surfacing. It represents a clearly expressed interlayer with a ferrite structure, the grain size in which increases as it approaches the fusion zone (Figure 1). The width of the interlayer becomes larger at the longer heating and decreases at the reduction of welding heat input and at the increase in the content of nickel in the electrode and the content of nitrogen in the composition of shielding gas. The effectiveness of influence of these indicators on the 


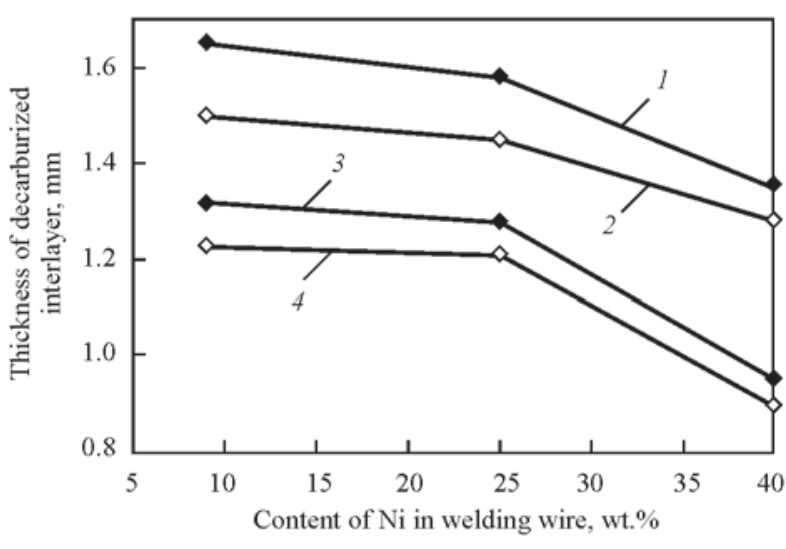

$a$

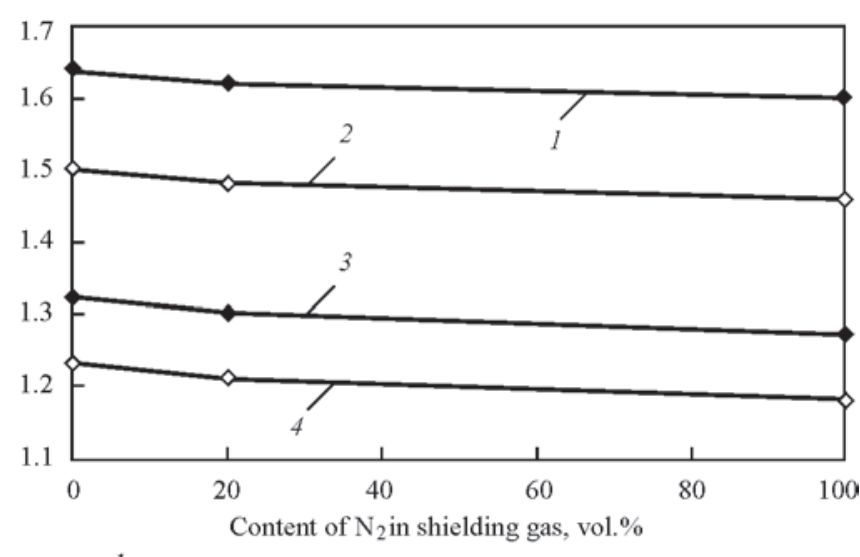

$b$

Figure 2. Dependence of ferrite interlayer width in the steel $20 \mathrm{HAZ}$ with single-layer austenitic deposit on content of nickel in welding wire (a) and nitrogen in shielding gas mixture (b) at heat input of $7.9(1,2)$ and $4.1(3,4) \mathrm{kJ} / \mathrm{cm}$ and heating at $550{ }^{\circ} \mathrm{C}$ for $3000(1,3)$ and $1000(2,4) \mathrm{h}$

width of ferrite interlayer was evaluated by comparing the values of the curve points shown in Figure 2.

The reduction in welding heat input from 7.9 to $4.1 \mathrm{~kJ} / \mathrm{cm}$ during welding using the wire with 9 and $25 \mathrm{wt} . \%$ Ni leads to reduction in the width of a ferrite interlayer approximately by 18 and $20 \%$ after 1000 and $3000 \mathrm{~h}$ heating, respectively. During welding using the wire with $40 \mathrm{wt} . \% \mathrm{Ni}$ the influence of heat input becomes more efficient, i.e. the width of an interlayer is reduced by approximately 28 and $30 \%$ after 1000 and $3000 \mathrm{~h}$ heating duration, respectively.

During welding with heat input of $7.9 \mathrm{~kJ} / \mathrm{cm}$ the application of welding wire with nickel content of 25 and $40 \%$ reduces the width of the decarburized interlayer approximately by 3 and $15 \%$, respectively, at heating duration of $1000 \mathrm{~h}$, and nearly by 4 and $18 \%$, respectively, at $3000 \mathrm{~h}$ heating. At the reduction of heat input to $4.1 \mathrm{~kJ} / \mathrm{cm}$, the effect of increasing the nickel content up to 25 and 40 wt.\% becomes more effective, i.e. approximately 4 and $18 \%$, respectively, at the heating duration of $1000 \mathrm{~h}$ and by nearly 26 and $28 \%$, respectively, at $3000 \mathrm{~h}$ holding. These relations are observed at any composition of shielding gas.

The alloying with nitrogen reduces the width of ferrite interlayer approximately by $5 \%$ during surfacing of metal of type $08 \mathrm{Kh} 20 \mathrm{~N} 9 \mathrm{G} 7 \mathrm{~T}$ and $08 \mathrm{Kh} 20 \mathrm{~N}-$ $25 \mathrm{M} 8 \mathrm{G} 8$ and the metal of type $08 \mathrm{Kh} 25 \mathrm{~N} 40 \mathrm{M} 7$ by $3 \%$ at any welding heat input. Such a change of decarburization is approximately equal both at mass fraction of nitrogen in the weld of $0.12 \%$ and also at $0.22 \%$, i.e. the dependence of its width in the joints of steel 20 on the amount of nitrogen in the austenitic metal in the investigated ranges was not detected.

Thus, the decrease in heat input of welding has a stronger influence on reduction of a ferrite interlayer width than an increase in nickel content up to 40 wt.\%. The influence of the weld metal alloying with nitrogen has the same effect on reduction in the width of a ferrite interlayer as an increase in nickel content up to $25 \%$.

The width of a ferrite interlayer for all the investigated variants of surfacing is within the range of the HAZ and is proportional to its width. The reduction of the HAZ width is facilitated not only by decrease in the heat input, but also by increase in the nickel content in the welding wire. At increase in mass fraction of nickel from 9 to $25 \%$ the HAZ width is 3-5\% decreased, and if to increase the nickel to $40 \%$ it decreases by $10-15 \%$. Along with that the metal structure is changed (Figure 3). The area of overheating in the near-weld zone during welding using the austenitic wire with $9 \% \mathrm{Ni}$ has a Widmanstatten ferrite without carbide precipitates, which is located inside

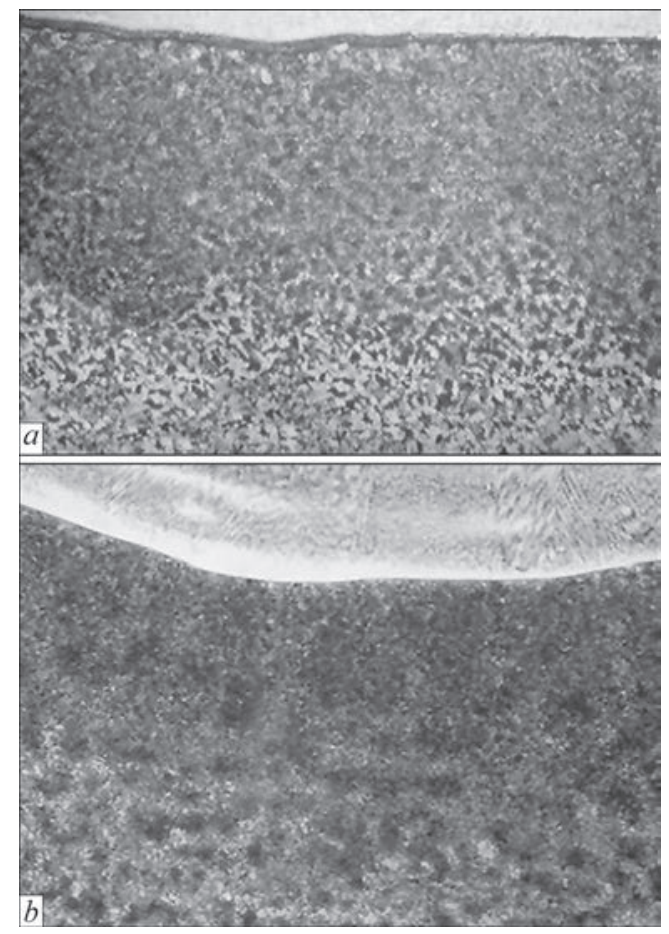

Figure 3. Microstructure $(\times 50)$ of HAZ metal of steel 20 with the austenitic deposited metal of type 08Kh20N9G7T (a) and 08Kh25N40M7 (b) in as-welded state 


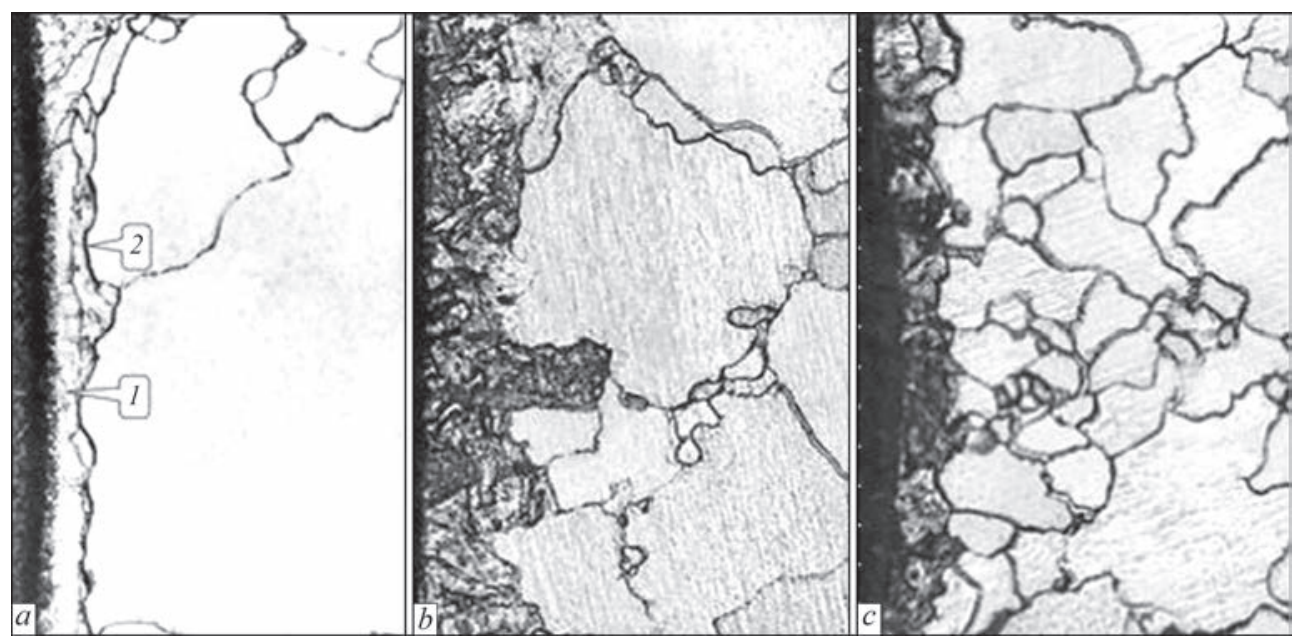

Figure 4. Microstructure $(\times 200)$ of metal of the submelted area and ferritic interlayer in the HAZ of steel 20 with austenitic metal of type 08Kh20N9G7T deposited in $\operatorname{Ar}(a)$ and $\mathrm{CO}_{2}+\mathrm{N}_{2}(b, c)$ at $7.9(a, b)$ and $4.1(c) \mathrm{kJ} / \mathrm{cm}$ heat imput, $550{ }^{\circ} \mathrm{C}$ heating for $3000 \mathrm{~h}: 1-$ submelted area; 2 - boundaries of ferrite grains adjacent to the submelting area

the austenite grains (Figure 3,a). During welding using the wire with $40 \% \mathrm{Ni}$ the overheating area has a bainite structure with the pearlite regions (Figure 3, b). It indicates the lesser degree of homogenization of austenite and the presence of carbides. To confirm this fact, the additional size of austenite grain was revealed at this region by metallographic etching in the water solution of picric acid with the addition of washing powder. It was found that the grain size is reduced from 3-4 to 5-6. To such a change in the value of grain size the change in the size of ferrite grains of a ferrite interlayer corresponds (Figure 4). The influence of increase in the nickel content on the change in the width of HAZ is explained [13] by decrease in the solidification temperature of the weld pool metal as well as the temperature and duration of heating the metal at the area of overheating.

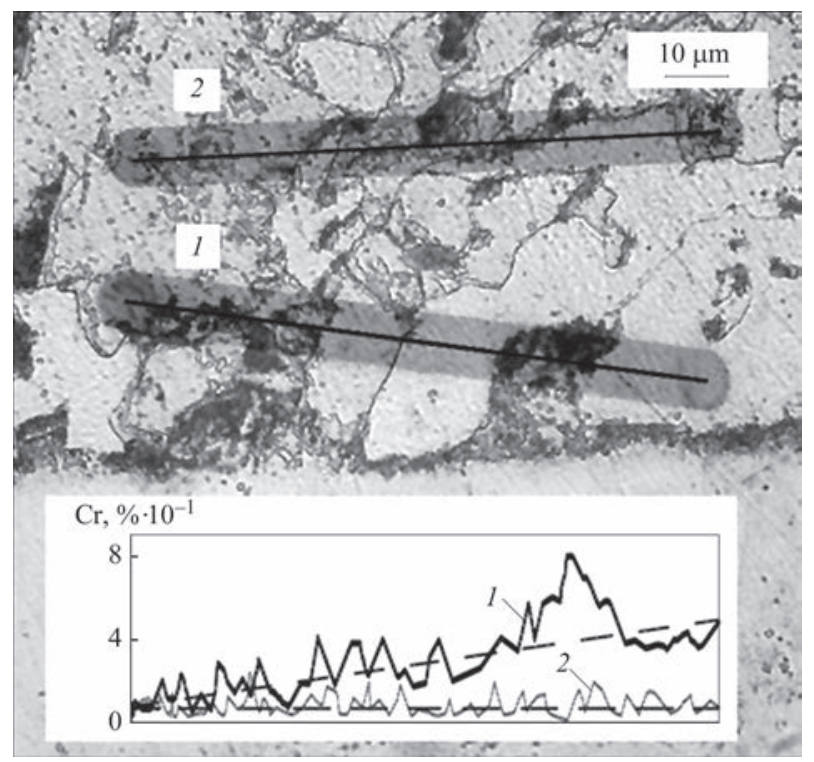

Figure 5. Distribution of chromium by traces 1 and 2 of microanalyzer probe in the near-weld zone of steel 20 with the austenitic deposited metal of 08Kh20N25M8G8 type
The alloying with nitrogen has a significant effect on the structure of submelting area of the near-weld zone, the sizes and shape of ferrite grains, especially those of the first series of the decarburized zone (see Figure 4).

The submelting area is revealed in the near-weld zone of all the investigated variants of surfacing in the form of an intermediate interlayer between the decarburized and carburized zones. The submelting of metal in that area is evidenced by the presence of alloying elements of a weld metal there, the content of which increases towards the fusion zone (Figure 5). The submelted area is contoured on the side of the decarburized zone by the boundaries of ferrite grains of the first series conjugated with it. Its thickness during surfacing at heat input of $7.9 \mathrm{~kJ} / \mathrm{cm}$ in $\mathrm{Ar}$ equals to $0.02-0.1 \cdot 10$, in $\mathrm{CO}_{2}-0.07-0.10$, in mixture of $\mathrm{CO}_{2}+\mathrm{N}_{2}-0.1 \cdot 10-0.15 \mathrm{~mm}$. The decrease in the heat input to $4.1 \mathrm{~kJ} / \mathrm{cm}$ leads to reduction of its thickness to $0.05-0.1 \cdot 10 \mathrm{~mm}$.

The structure of the submelted area in the nearweld zone of deposit, performed in Ar, is ferrite, with narrow, fine grains elongated mainly along the fusion zone (see Figure 4, b). The linear X-ray spectral microanalysis shows a significant reduction of carbon in that area (highlighted by dash line in Figure 6, a), that evidences of its decarburization.

The ferrite grains of the first series are very large (2-3 according to GOST 5639-82). They were formed, apparently, due to collective recrystallization as a result of grains fusion at dissolution of low-resistant carbides in the conditions of decarbonization. The boundaries between these grains and the submelted area are mostly oriented along the fusion zone. These boundaries are intensively etched over the entire length during the metallographic etching and have a high carbon content (1.1-1.8 wt.\%). Apparently, it 


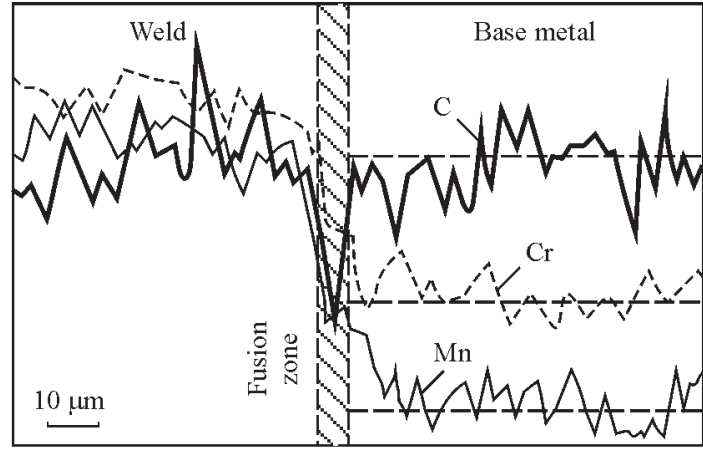

$a$

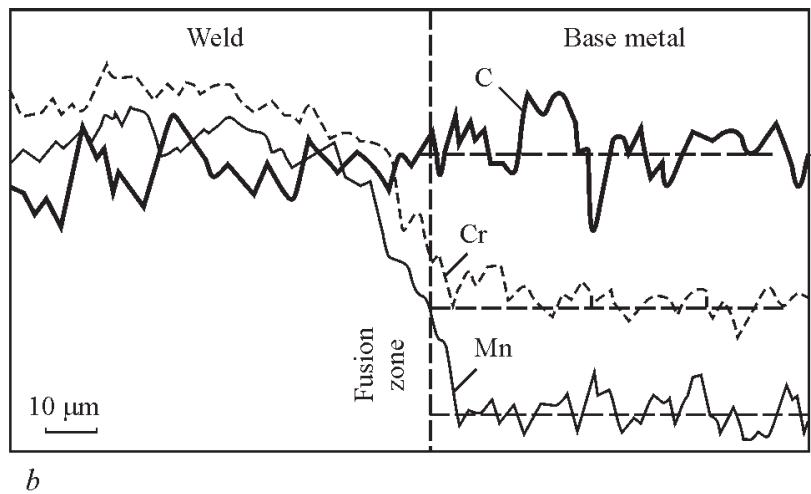

Figure 6. Distribution of carbon in fusion zone of welded joints of steel $15 \mathrm{Kh} 5 \mathrm{M}$ with austenitic metal of 08Kh20N9G7T type deposited in $\operatorname{Ar}(a)$ and $\mathrm{CO}_{2}+\mathrm{N}_{2}(b)$ at $550{ }^{\circ} \mathrm{C}$ heating for $3000 \mathrm{~h}$

evidences of the film precipitation of the more alloyed carbides there. The hardness of metal of the submelted area near the ferrite grains is equal to HV0.2-118 and near the dark etched carburized zone it grows to $H V 0.2-146$. At the carburized zone the hardness of metal is equal to HV0.2-360-667.

At the submelting area of the deposits performed in $\mathrm{Ni}_{2}$-containing shielding gas, as compared to those performed in Ar, the structure of tempering sorbite (the main field) with nitride particles and fine grains is formed instead of ferrite structure (see Figure $4, b$ ). The hardness of metal with such a structure is higher, i.e. HV0.2-160-180, and that of ferrite grains adjacent to it is $H V 0.2-120-146$. In the carburized zone the hardness of metal is decreased to HV0.2-280-445. At the distribution curve of carbon (see Figure $6, b$ ), obtained by X-ray microanalysis, the carbon reduction in the submelting area is absent, at the same time, numerous small peaks were revealed there, formed, apparently, by carbonitrides. At the area of the transition layer of this curve the carbide peaks have a smaller height and width, which indicates a reduction in carbon content in the carbide particles and their more uniform distribution. In the decarburized interlayer the value of the first series ferrite grains, which are mated with the submelted area, decreased more than twice. Their boundaries are more disoriented relative- ly to the fusion zone (see Figure $4, b$ ) and are less etched. It indicates the fact that the process of decarburization and collective recrystallization gained lower propagation and the film carbide precipitates are absent at the boundaries. The disorientation of boundaries of the first series ferrite grains is also caused by their adjacency with the fine grains of the submelted area. The decrease in the density of carbides clustering at the boundaries is apparently caused by increase in the area of surfaces, where the carbon is concentrated, formed by dispersed grains and nitride particles.

When decreasing the welding heat input from 7.9 to $4.1 \mathrm{~kJ} / \mathrm{cm}$ the structure of metal in the submelted area of the near-weld zone of all the investigated variants of surfacing remains unchanged, but the value of grains both in the submelted area as well as that of the first series ferrite grains of the decarburized interlayer becomes even smaller (see Figure 4, c).

The resistance of welded joints of dissimilar steels against thermal embrittlement was evaluated according to the procedure of work [14] by testing on static bending of specimens with artificial lack of penetration, which plays the role of a concentrator in the fusion zone. The welded joints of steel 20 with the weld metal of type $08 \mathrm{Kh} 20 \mathrm{~N} 9 \mathrm{G} 7 \mathrm{~T}$ were tested produced in $\mathrm{CO}_{2}+2 \% \mathrm{~N}_{2}$ and with the weld metal of type $08 \mathrm{Kh} 25 \mathrm{~N} 40 \mathrm{M} 7$ produced in $\mathrm{Ar}$, in the state after

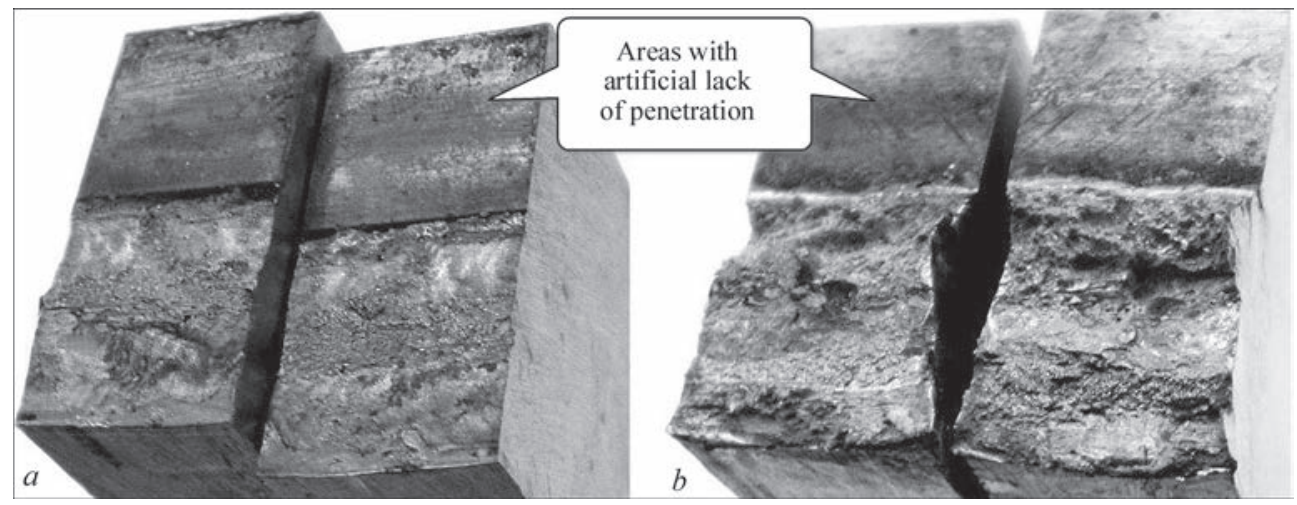

Figure 7. Fracture surfaces of specimens with artificial lack of penetration in the fusion zone of steel 20 joints with austenitic weld metal of 08Kh25N40M7 (a) and 08Kh20N9G7T (b) type produced in $\mathrm{Ar}$ and $\mathrm{CO}_{2}+2 \% \mathrm{~N}_{2}$, respectively, after testing on static bending 
heating at $550{ }^{\circ} \mathrm{C}$ for $3000 \mathrm{~h}$. The application of specimens with artificial lack of penetration allowed localizing the deformation during bending in the fusion zone. The specimens of welded joints, produced in $\mathrm{Ni}_{2}$-containing gas withstand 1.5-2 times higher fracture load and have a greater bending angle $\left(50-80^{\circ}\right)$ than the specimens of welded joints, produced in $\mathrm{Ar}$ $\left(5-15^{\circ}\right)$. In the first variant of welded joint the fracture of specimens is tough and deviates from the fusion zone to the base metal, and in the second variant it is brittle (see Figure 7) over the carburized zone and the boundaries of ferrite grains of the first series, coupled with the submelted area of the fusion zone.

\section{Conclusions}

1. At a long high-temperature heating of joints of dissimilar steels with the austenitic weld, not alloyed with nitrogen, the film carbide precipitates are formed in the conditions of structural and phase instability between the fusion zone and the HAZ, which is one of the causes of brittle fracture.

2. The increase in nickel content in the austenitic weld and the reduction in welding heat input contribute to the decrease in the width of a ferrite interlayer in the HAZ of pearlite steel at high-temperature heating, but it does not prevent the formation of film carbide precipitation and metal embrittlement.

3. The decisive factor, influencing the reduction in the width of a ferrite interlayer of the increased nickel content in the austenitic weld and low welding heat input, is the reduction in metal overheating and degree of degradation of carbides in the HAZ.

4. During long high-temperature heating the austenitic weld metal alloying with nitrogen, the formation of nitride particles and grains refinement contribute to increase in the structure stability, inhibition of devel- opment of carbide reactions and reduction in structural heterogeneity, as well as a more uniform distribution of carbides in the fusion zone with pearlite steel, that reduces the thermal embrittlement of welded joints of dissimilar steels.

1. Gotalsky, Yu.N. (1981) Welding of dissimilar steels. Kiev: Tekhnika.

2. Zemzin, V.N. (1966) Welded joints of dissimilar steels. Moscow: Mashinostroenie.

3. Livshits, L.S., Khakimov, A.N. (1989) Metals science of welding and heat treatment of welded joints. $2^{\text {nd }}$ ed. Moscow: Mashinostroenie.

4. Kirilichev, N.V., Gotalsky, Yu.N. (1980) Peculiarity of structural heterogeneity in fusion zone of multilayer austenitic weld with pearlitic steel. Avtomatich. Svarka, 9, 28-32.

5. Safonov, A.N., Radchenko, R.D., Chobanyan, V.A. (1993) Investigation of structural transformations in surface layers of low-alloy steel welded joints after laser treatment and subsequent heating. Svarochn. Proizvodstvo, 1, 4-7.

6. Lipodaev, V.N., Snisar, V.V., Belchuk, M.V. et al. (1991) Specifics of brittle fracture of dissimilar welded joint with high-nickel weld metal. Avtomatich. Svarka, 10, 6-9.

7. Snisar, V.V., Lipodaev, V.N., Elagin, V.P. et al. (1991) Effect of nitrogen alloying of austenitic weld on development of structural heterogeneity in fusion zone with pearlitic steel. Ibid., 2, 10-14.

8. Krishtal, M.A. (1972) Diffusion mechanism in iron alloys. Moscow: Metallurgiya.

9. Minkevich, A.K. (1968) Chemical heat treatment. Moscow: Mashinostroenie.

10. Lakhtin, Yu.M., Arzamasov, B.N. (1985) Chemical heat treatment of metals: Manual for institutes of higher education. Moscow: Metallurgiya.

11. Zhitnikov, N.P., Zaks, I.A. (1971) Effect of nitrogen on structure of austenitic weld metal. Svarochn. Proizvodstvo, 8, 5-9.

12. Elagin, V.P., Snisar, V.V., Lipodaev, V.N. et al. (1995) Mechanized welding of $15 \mathrm{Kh} 5 \mathrm{M}$ steel without heating and heat treatment. Avtomatich. Svarka, 8, 19-23.

13. Makarov, E.L. (1981) Cold cracks in welding of alloy steels. Moscow: Mashinostroenie.

14. Bojkova, K.I., Chizhik, A.I., Zemzin, V.N. (1975) Method of evaluation of susceptibility to brittle fracture of welded joints on criteria of fracture mechanics. Avtomatich. Svarka, 2, 14.

Received 15.05.2016 